\title{
Dental Caries from a Molecular Microbiological Perspective
}

\author{
B. Nyvad ${ }^{\text {a }}$ W. Crielaard ${ }^{\text {b }}$ A. Mira ${ }^{c} \quad$ N. Takahashid ${ }^{d}$ D. Beighton ${ }^{e}$ \\ a Department of Dentistry, HEALTH, Aarhus University, Aarhus, Denmark; ${ }^{b}$ Department of Preventive Dentistry, \\ Academic Centre for Dentistry Amsterdam, University of Amsterdam and VU University Amsterdam, Amsterdam, \\ The Netherlands; ${ }^{\circ}$ Center for Advanced Research in Public Health, Valencia, Spain; ${ }^{d}$ Division of Oral Ecology and \\ Biochemistry, Tohoku University Graduate School of Dentistry, Sendai, Japan; ' Department of Microbiology, \\ Dental Institute, King's College London, London, UK
}

\section{Key Words}

$16 \mathrm{~S}$ rRNA $\cdot$ Dental caries $\cdot$ Molecular microbiology ·

Next-generation sequencing $\cdot$ Metagenomics •

Metatranscriptomics $\cdot$ Metabolomics

\begin{abstract}
Dental caries results from an imbalance of the metabolic activity in the dental biofilm. The microbial communities of teeth have traditionally been studied by standard cultural approaches. More recently, cloning and sequencing of the $16 \mathrm{~S}$ rRNA gene have been used to characterize the microbial composition of the oral biofilm, but the methodological limitations of this approach have now been recognized. Nextgeneration high-throughput sequencing methods have the potential to reveal the composition and functioning of the biofilm by means of metagenomic and metatranscriptomic analyses. Currently available high-throughput sequencing approaches are reviewed and discussed in relation to studying the biofilm associated with dental caries. Important in understanding the dynamic processes in caries is the metabolic activity of the biofilm; metabolome analysis is a new tool that might enable us to assess such activity. As caries is a localized disease, it is essential that biofilm samples are taken from precisely determined tooth sites; pooling samples is not appropriate. This paper presents the case that culture-
\end{abstract}

based studies are important, but that the fullest understanding of the role of the biofilm in the caries process will only come from an integrated approach determining biological function and metabolic output.

Copyright $\odot 2012$ S. Karger AG, Basel

Molecular methods have added new and exciting dimensions to the study and understanding of medical microbiology, microbial pathogenicity and host-bacterial interactions. They have highlighted the fact that most of the bacteria colonizing the human body cannot be characterized by conventional cultivation methods. The first molecular microbiological study appeared in dentistry based on sequence analysis of the 16S rRNA genes only 10 years ago. The study showed an unsuspected high diversity of the subgingival flora along with a considerable amount of unidentified phylotypes [Kroes et al., 1999]. Currently, molecular techniques have allowed us to identify about 620 predominant oral bacterial species, $35 \%$ of which have not yet been cultured in vitro [Paster and Dewhirst, 2009; Dewhirst et al., 2010]. However, a single study has proposed that there may be several thousands of species inhabiting the oral cavity [Keijser et al., 2008].

\section{KARGER}

Fax +4161306 1234 E-Mail karger@karger.ch www.karger.com

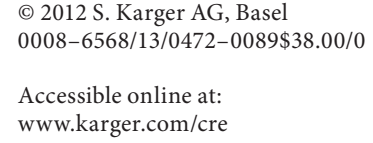

\section{Bente Nyvad}

Department of Dentistry, HEALTH

Aarhus University, Vennelyst Boulevard 9

DK-8000 Aarhus C. (Denmark)

E-Mail nyvad@odont.au.dk 
In view of the overwhelming diversity of the oral microbiota, it may not come as a surprise that caries researchers have been relatively slow in adopting the new molecular techniques. The question is: How can we apply the new technologies in a meaningful manner to increase our knowledge about caries? The aim of this paper, which is based on presentations given at the ORCA (European Organization for Caries Research) Saturday Afternoon Symposium in Kaunas, Lithuania in July 2011, is, therefore, to (1) provide an overview of the molecular microbiological and metabolomic techniques available today, (2) report on the results obtained by these techniques in relation to dental caries, and (3) discuss how molecular studies may help us to better understand and manage caries in the future.

\section{Setting the Stage}

This paper is rooted in the relatively recent appreciation that the majority of bacteria on teeth live in structured multispecies communities [Palmer et al., 2011]. The metabolic processes in such communities are highly dynamic. However, under normal physiological conditions, the de- and remineralization processes in the supragingival biofilm are balanced and unlikely to cause harm to the teeth. Only when the de- and remineralization balance is disturbed, e.g. by frequent carbohydrate exposure and/or decreased salivary clearance of foods, may the homeostasis in the biofilm break down and result in compositional changes of the biofilm and caries [Marsh, 1994]. Such ecological disruptions of the microbial community are prone to occur because of microbial acid-induced adaptation and selection processes [Takahashi and Nyvad, 2008, 2011]. Under severe and prolonged acidic conditions, more aciduric bacteria become dominant, involving not only Streptococcus mutans and Lactobacillus, but also aciduric strains of non-mutans streptococci, Actinomyces, bifidobacteria and yeasts. Thus, many acidogenic and aciduric bacteria are involved in caries, supporting the notion that caries etiology is probably complex and multi-faceted [Takahashi and Nyvad, 2008, 2011; Peterson et al., 2011].

Indeed, microbial culturing has provided considerable knowledge on the microorganisms associated with dental caries, but unfortunately this approach is (by definition) limited by the fact that it focuses on cultivable microorganisms. As has been frequently underlined (see Wade [2002]), many oral bacteria cannot be cultivated and, therefore, conclusions are drawn on an incomplete pic- ture. With this in mind, and because we have recently realized that there are also microbiological processes that actively maintain dental health, molecular microbial analyses have been developed and exploited to give a more complete overview of the oral ecology in health and disease.

\section{Traditional Molecular Microbial Analyses and Next-Generation Sequencing Tools to Study Oral Molecular Ecology}

Almost all molecular microbial analyses targeted at the identification of microorganisms are based on the $16 \mathrm{~S}$ ribosomal RNA gene, which can be analyzed after DNA extraction from the bacterial samples. This RNA molecule is an essential building block of the bacterial ribosome and, because it mutates relatively slowly, it can be used for bacterial phylogeny. In oral microbiology (for a recent review, see Wade [2011]) and caries research, the $16 \mathrm{~S}$ rRNA gene has also been widely used for taxonomy and to display differences in the complexity and composition of saliva and plaque samples. However, this approach, just like cultural methods, has systematic limitations which make the interpretation of $16 \mathrm{~S}$ rRNA sequencing data to describe the microbial composition of an oral sample problematic (see below).

\section{Denaturing Gradient Gel Electrophoresis}

Denaturing gradient gel electrophoresis outlines oral microbial ecology using the differences in mobility of partially melted double-stranded PCR-amplified 16S rRNA genes or gene fragments, during electrophoresis in a polyacrylamide gel containing a gradient of denaturant [Muyzer et al., 1993]. 16S rRNA genes with different sequences will have a different melting behavior and therefore end up at different positions in the gel. After visualization of the DNA in the gel, conclusions can be drawn on differences in the presence/absence of bands in samples and (differences in) the complexity of samples. As this technique is relatively cheap, easy to perform and reliable, it has also found a secure place in caries research. Unfortunately, it is not a quantitative technique and, certainly in complex samples, it is not really possible to relate specific bands to a given species; it is also difficult to compare different gels, certainly when dealing with samples containing many species. Nevertheless, it is an excellent technique for the (initial) analysis of microbial diversity and microbial complexity in saliva or plaque samples. In caries research, two recent papers [Li et al., 2007; Jiang et 
al., 2011] while exploiting the denaturing gradient gel electrophoresis technique, study species composition in different stages of dental caries in children. Both studies showed that microbial species richness and microbial complexity decrease during the caries process.

\section{PCR-Based Methods}

Polymerase chain reaction (PCR) methods, when systemically evaluated and optimized, allow a relatively cheap, easy-to-perform and reliable method for the detection of cariogenic pathogens. Real-time quantitative PCR [(q)PCR] is mostly used nowadays because it allows both specificity for and quantification of pathogens (for a recent evaluation and details of the technique please see Smith and Osborn [2009]). Primers (and sometimes internal probes) are designed to be specific for the $16 \mathrm{~S}$ rRNA gene (or another gene) of a desired species. This indeed makes this method excellent for the quantitative analyses of targeted species, but has the disadvantage that no evaluation is made of all the other microorganisms present. qPCR methods can be designed to be 'multiplex', allowing simultaneous detection of 3 or 4 pathogens in one reaction (see Ciric et al. [2010]) and there are alternative $16 \mathrm{~S}$ rRNA gene-based PCR methods that can follow 9-20 oral microorganisms [Terefework et al., 2008; Pham et al., 2011], but still, the full complexity of the oral community cannot be probed by qPCR. Two recent articles using qPCR targeted to cariogenic pathogens showed that both S. mutans and S. sobrinus are associated with early childhood caries [Choi et al., 2009; Palmer et al., 2010].

\section{$16 S$ rRNA Gene Microarrays}

As a high-throughput tool for the characterization of microbial communities, taxonomic microarrays have been developed for several different types of environmental samples [Wagner et al., 2007]. On these microarrays, probes are spotted on a solid substrate such as glass. Each probe is composed of a $16 \mathrm{~S}$ rRNA gene sequence complimentary to a target species. $16 \mathrm{~S}$ rRNA genes present in an (oral) microbial community are PCR-amplified using universal primers, labeled and hybridized on the array. In this way, microarrays can be used to 'fingerprint' bacterial communities and identify shifts/associations with oral infections (see Call et al. [2003] for an overview).

A taxonomic microarray has been developed by the Forsyth Institute [Preza et al., 2009; http://mim.forsyth. org] specifically for oral microbial ecology. This Human Oral Microbe Identification microarray (HOMIM) can detect 272 of the most prevalent oral bacterial species, including several that have not yet been cultivated [http:// mim.forsyth.org]. It has been used in caries research for probing plaque from healthy and carious root surfaces in elderly subjects [Preza et al., 2009]. It has been shown that bacterial diversity was higher in healthy compared to diseased subjects. Several species of Lactobacillus and Pseudoramibacter alactolyticus were shown to be associated with root caries. Actinomyces was found more frequently in healthy elderly subjects [Preza et al., 2009]. The HOMIM was also used for screening oral ecology in patients in West Virginia [Olson et al., 2011]. In contrast to the root caries study, in this paper it was shown that microbial diversity is increased in the subgingival plaque of diseased subjects.

The HOMIM, as well as a similar custom-made array [Crielaard et al., 2011] have been proven to indeed be 'high-throughput', processing many samples in a reproducible way. When the microarrays are calibrated carefully, they can be quantitative; otherwise only semiquantitative results are obtained. Both microarrays have the option to detect around 300 different species with a sensitivity equal to that of culturing. The advantage of custom-made arrays lies in the fact that probes can be specifically targeted to individual patient groups. A major disadvantage of any technique using probes is the fact that only microorganisms that are targeted by the probes can be detected. Microarray is not an open-ended technique and although it is easy to perform, it is (still) quite expensive.

\section{Checkerboard Hybridization}

Although not targeted to the $16 \mathrm{~S}$ rRNA gene, an alternative array technique to study oral microbial ecology is the checkerboard DNA-DNA hybridization technique. This technique uses whole genomic DNA probes and is sensitive, semiquantitative and relatively inexpensive. In a study on periodontal diseases, Socransky et al. [2004] developed a 40-species-specific DNA-DNA hybridization checkerboard to detect oral bacteria. The technique has the advantage of flexibility in the choice of targets and variations of the technique have indeed also been targeted towards studies on caries risk and epidemiology [Sissons et al., 2007; Dahlén et al., 2010; Kanasi et al., 2010]. As whole genome probes are used, considerable cross hybridization is possible in checkerboard studies; so there can be no certainty that there are no cross-hybridization reactions resulting in incorrect quantification of species. An additional drawback of the technique lies in the fact that only a limited number of species are studied simultaneously, so that it is clearly not an open-ended approach. 


\section{Open-Ended Approaches and Next-Generation}

\section{Sequencing}

The open-ended approach (i.e. no selection for specific species) that has been most widely used for oral microbial communities is the $16 \mathrm{~S}$ rRNA gene clone-library approach. In this approach, the 16s rRNA genes present in a certain environment are amplified by PCR using universally conserved primers. The $16 \mathrm{~S}$ rRNA genes are subsequently cloned into Escherichia coli, for example, and the clones are sequenced using traditional Sanger sequencing methods (see Paster et al. [2006]). Currently, by using this technique, several hundred predominant bacterial species have been estimated to be present in the oral cavity [Dewhirst et al., 2010], and from the first indications of next-generation sequencing (NGS) approaches [Keijser et al., 2008] we know that there are less predominant oral microorganisms waiting to be identified.

NGS approaches (like 454 pyrosequencing) differ from the traditional Sanger method in the fact that they do not involve a cloning step, but, most importantly, that they can retrieve millions of partial $16 \mathrm{~S}$ rRNA gene sequences in one sequencing run [Metzker, 2010]. A comparison between endodontic communities analyzed by the clone-library approach and NGS by Li et al. [2010] revealed an increase from 25 to 179 in recovered genera in the samples, underlining the potential of NGS in studying oral infections. Indeed, since the first use of NGS for oral communities in 2008 [Keijser et al., 2008], there has been an avalanche of NGS studies directed towards oral infections. At the moment, unfortunately, there are still a few drawbacks in using NGS. Although cheaper and faster than 16S rRNA cloning, most NGS techniques, and certainly 454 pyrosequencing, are quite expensive, and derived sequences may be too short to permit identification at the species level. Pooling samples and using DNA barcodes to trace back sequences to specific samples (see Ling et al. [2010] and Crielaard et al. [2011]) can only partly compensate for this. Another complication is the fact that the bioinformatics software for dealing with possible sequencing errors and handling the large amount of data is still in development [Cole et al., 2009]. Nevertheless, a recent review on NGS approaches to understand the oral microbiome [Zaura, 2012] discusses several novel computational tools and algorithms and shows that helpful bioinformatics pipelines, also in this field, are now being implemented.

It has to be kept in mind that improvements in sequencing technology are being introduced extraordinarily fast. Pyrosequencing and Illumina dye sequencing, for instance, are approaching read lengths of 800 and
$400 \mathrm{bp}$, respectively, and other sequencing platforms provide easier library preparation, like Ion Torrent ${ }^{\mathrm{TM}}$ chip sequencing, which produces a million 200-bp reads in a few hours [Jünemann et al., 2012].

Third-generation technologies include the single-molecule sequencing by Pacific Biosciences and the Oxford nanopore system where read lengths of several kbp are being obtained, although currently at the expense of a high error rate [Schadt et al., 2010]. In addition, Helicos has developed a system for directly sequencing RNA, obviating the need for retrotranscribing to cDNA which would avoid biases and imply a phenomenal tool for metatranscriptomic analysis.

In caries research, NGS has been used to analyze the oral microbiota in Chinese children with dental caries [Ling et al., 2010]. This cross-sectional study, which revealed almost 42,000 unique sequences from 60 children with and without caries, indicated that the genera of Streptococcus, Veillonella, Actinomyces, Granulicatella, Leptotrichia and Thiomonas in plaque are significantly associated with dental caries. Another recent study that compared the saliva microbiome (i.e. all microorganisms present in saliva) of adults with and without caries using NGS on the 16S rRNA gene [Yang et al., 2012] found that caries microbiomes were significantly more variable in community structure than 'healthy' microbiomes. This remarkable finding that 'healthy' microbiomes are also or even more conserved than caries microbiomes was also found in a study where NGS and microarrays were combined [Crielaard et al., 2011]. In this study, the microbial composition of saliva in children $(n=74$, aged 3-18 years) was related to their caries status. A caries-free oral status was significantly associated with higher amounts of Porphyromonas catoniae and Neisseria flavescens.

\section{Other Molecular Approaches for Revealing Microbial Diversity: Beyond 16S rRNA}

As discussed in the previous sections, cloning and sequencing $16 \mathrm{~S}$ rRNA genes have been the preferred molecular methods used to identify individual bacterial and archeal taxa of oral samples. However, this approach is clearly limited and significantly underestimates the microbial diversity of the samples investigated. Systematic errors associated with the detection of 'high G+C organisms', including the Actinomyces and Bifidobacteriaceae, have been demonstrated such that these significant taxa are not accurately determined yet readily detected using culture techniques [Munson et al., 2004; Beighton et al., 
2008; Frank et al., 2008; Preza et al., 2008]. Other issues relate to the inability of even full $16 \mathrm{~S}$ rRNA sequences to differentiate between species, and this is of particular concern when investigating the microbiota associated with the caries process, as not all Streptococcus, Lactobacillus, Veillonellae and Actinomyces can be differentiated using 16S rRNA sequencing [Naser et al., 2007; Bishop et al., 2009; Henssge et al., 2009; Michon et al., 2010]. The use of shorter sequences compounds this problem, making the identification of many clones possible only to the genus level. The determination of the proportional composition of a microbial population is further made difficult by not all of the $16 \mathrm{~S}$ rRNA sequences in a given isolate being identical [Vásquez et al., 2005; Vos et al., 2012] and not all species contain the same number of 16S rRNA sequences [Pei et al., 2010; Bodilis et al., 2012]. So while cultural approaches to investigating the microbial composition of an oral sample certainly have limitations, the use of $16 \mathrm{~S}$ rRNA sequencing has its own set limitations which need to be acknowledged and their influence on derived data need to be discussed.

The diversity of the oral microbiota is even more varied than is apparent from $16 \mathrm{~S}$ rRNA sequencing data, as these categorize bacteria only on the basis of their $16 \mathrm{~S}$ rRNA sequence without reference to the phenotype of the organism. It is the phenotype that is important in determining the role of an organism in the caries process [Takahashi and Nyvad, 2008]. It has been known since bacteria were first isolated that members of the same species do not exhibit the same phenotype, e.g. their ability to ferment a range of carbohydrates will vary within a single species. The first appreciation of intraspecies phenotypic diversity was the demonstration that the bacteriocin-sensitivity profiles of $S$. mutans could be used to monitor transmission from mothers to their infants [Rogers, 1977; Berkowitz and Jones, 1985]. These observations were confirmed in restriction fragment length polymorphism studies and demonstrated extensive genomic diversity within S. mutans [Li and Caufield, 1995]. The genomic diversity of $S$. mutans was confirmed using PCR-based DNA fingerprinting studies and in more sophisticated genetic studies [Mattos-Graner et al., 2001; Waterhouse and Russell, 2006]. DNA fingerprinting studies like repetitive extragenic palindromic PCR of other taxa, including Actinomyces, Veillonella and nonmutans streptococci demonstrated that these taxa are also highly diverse at the genome level [Alam et al., 1999; Brailsford et al., 1999; Arif et al., 2008]. Examination of the diversity of oral taxa using a multilocus sequencing approach [Maiden et al., 1998], in which internal frag- ments of 7 housekeeping genes were sequenced, concatenated and aligned, has shown that most independent members of all the species investigated, including $S$. $m u$ tans, $S$. oralis, S. sanguinis, S. salivarius, A. oris, A. naeslundii and $P$. gingivalis are distinct [Delorme et al., 2007; Nakano et al., 2007; Do et al., 2009; Henssge et al., 2009; Do et al., 2011; Enersen, 2011]: a common feature of commensal bacteria.

Knowing the identity of an organism does not necessarily mean that the phenotype is apparent. In a study of the aciduricity of non-mutans streptococci isolated from root caries lesions, van Houte et al. [1996] reported that $78 \%$ of isolates from carious lesions were more acidogenic (final $\mathrm{pH}<4.2$ ) than those isolates from caries-free subjects of which only $16 \%$ produced the same final $\mathrm{pH}$ in glucose media. We [Alam et al., 2000] isolated S. oralis strains from adult caries-free individuals on media of different $\mathrm{pH}$ values and used repetitive extragenic palindromic PCR to compare the isolates. Those isolated at $\mathrm{pH}$ 5.2 were distinct from those recovered at $\mathrm{pH}$ 7.0, demonstrating that different genotypes may have a different phenotype. In a study of the microbiota associated with refractory endodontic infections we isolated many Propionibacterium acnes, identified on the basis of $16 \mathrm{~S}$ rRNA sequencing, but subsequent recA typing demonstrated that the majority of isolates from the infections were either type II or type III associated with infections of medical implants, rather than type I, routinely isolated from the skin [Niazi et al., 2010].

While this clearly shows that the diversity of bacteria exceeds that apparent from simple 16S rRNA sequencing, the genomic diversity even within a species may be profound. The concept of a 'core genome' has been developed: all the genes present in all members of a species represent the core genome. Other genes are dispensable and are not essential for survival and proliferation, but might be important for survival in specific habitats. In a study of 44 S. pneumoniae genomes [Donati et al., 2010], it was estimated that the total number of genes in these strains was 3,221, but of these only 1,666 were present in all genomes - 1,555 were present in more than one genome but another 389 genes (12\%) were present in only one of the 44 genomes. Investigations into $E$. coli genomes, larger than the S. pneumoniae genome, reported that amongst 20 commensal and pathogenic strains, approximately 18,000 genes were found, but only around 2,000 were common to all isolates. In both studies, the dispensable genomes were acquired by horizontal gene transfer [Touchon et al., 2009]. 


\section{Metagenomic and Metatranscriptomic Approaches}

The pyrosequencing of $16 \mathrm{~S}$ rRNA PCR products has allowed a reasonably complete description of the oral microbiota, as the number of sequences obtained per sample has passed from tens in traditional cloning studies to thousands, and it implies a considerable reduction in time and economic cost. However, the PCR step introduces well-known biases due to the overamplification of some taxonomic groups and the underrepresentation of others, especially under some experimental conditions like high annealing temperature [Sipos et al., 2007] or the use of different primer pairs [de Lillo et al., 2006]. In addition, it has to be kept in mind that the taxonomic composition of oral samples may give little information about the functional output of microbial communities. This is especially important for the study of dental caries, as it has been proposed that different bacterial consortia may be responsible for acid production; aiming at identifying specific organisms associated with dental caries could therefore prove to be elusive [Takahashi and Nyvad, 2011]. Metagenomics provides, however, a tool to access the genetic information of a whole microbial community and to gain insights about the function of its members. It consists of the study of bacterial communities directly via their total DNA content, therefore obviating the need for traditional culturing techniques and PCR [Mullany et al., 2008].

Two approaches have been followed to study the DNA extracted from oral samples: cloning and direct DNA sequencing. The former involves fragmentation of the DNA and cloning into a vector which is inserted within a host, typically E. coli. By repeating this process thousands of times, a metagenomic library is obtained which contains multiple clones, each of them with a different piece of DNA from the sampled community. A great advantage of this method is that the inserted DNA can be not only sequenced but also expressed if it is compatible with the host, and therefore the researcher can study the functions encoded, including those present in uncultured organisms. In addition, the libraries can be frozen and kept for future reference. An interesting application of this technique was performed by Diaz-Torres et al. [2006], who cloned DNA from saliva and plaque samples into TOPO$\mathrm{XL}$ plasmids and fosmids, which are small (3-kb on average) and large (around 40-kb) vectors, respectively. Four metagenomic libraries were screened for antibiotic resistance, and clones resistant to tetracycline and amoxicillin were found in all libraries but clones resistant to gentamicin were detected in only three of them. In addition, the clones giving a positive result in a tetracycline-resistance screening were later studied by PCR using specific primers, identifying the tet genes responsible for the resistance [Diaz-Torres et al., 2006]. An additional advantage of metagenomic libraries is that the inserted DNA can be sequenced later, gaining access to the genetic information of all present bacteria. This can be achieved by traditional Sanger sequencing from the vector ends or, more recently, by directly pyrosequencing the total vector DNA [Ghai et al., 2010]. Metagenomic vectors able to accommodate large DNA inserts including fosmids or bacterial artificial chromosomes have the advantage of cloning whole operons, increasing the chances of detecting the desired function. This approach was followed by Seville et al. [2009], who used bacterial artificial chromosome libraries to detect antibiotic resistance genes and several transposon integrases in oral and fecal samples by hybridizing the metagenomic DNA against a microarray containing specific probes for the genes of interest. Another alternative to identify the genes responsible for a particular function in metagenomic libraries is the random mutation of all genes in the cloned DNA. By repeating the functional screening in the mutated clones and selecting those where the activity is lost, the genes providing the activity can be identified [Stahlhut et al., 2010].

A second metagenomic approach involves the direct sequencing of the bacterial community total DNA. This has the advantage of obviating the need for cloning, which simplifies sample preparation enormously and prevents the cloning bias which appears to be fairly frequent when the inserted DNA has a toxic effect on the host, preventing its cloning [Sorek et al., 2007]. The methods for direct sequencing of oral samples were first tested on a dental plaque sample from a healthy donor, employing the Roche pyrosequencing and the Illumina Solexa technologies, producing 177,000 and 16 million sequence reads by each technology, which produced an average read length of 400 and $75 \mathrm{bp}$, respectively. The enormous coverage in the Illumina reads can be used to assemble the DNA in longer fragments, compensating their short length, and a combination of both sequencing technologies was found optimal to obtain long assembled pieces which can then be studied for taxonomic and functional analyses [Xie et al., 2010]. The longer length of pyrosequencing reads, especially with the recently launched titanium-plus system (over 650 bp on average) is normally sufficient for a direct recognition of gene function by sequence similarity, allowing a comparison of the functions encoded by the oral microbiota from different individuals. This approach was first performed by comparing su- 
pragingival dental plaque samples from 8 individuals who varied in health status [Belda-Ferre et al., 2011]. Functional assignment of 1.5 million pyrosequencing reads against different databases was able to identify a putative function in $50-60 \%$ of the sequences, showing that a large pool of genes from oral bacteria has still to be functionally characterized. Interesting differences were found between samples, as individuals who had never suffered from dental caries had an overrepresentation of genes encoding antimicrobial peptides and quorumsensing genes, among others, whereas samples from individuals with cavities had a high frequency of genes involved in functions such as iron scavenging and oxidative and osmotic stress. This powerful method reveals the functional contribution of complex oral bacterial populations, and future studies should aim at identifying whether different bacterial consortia can be responsible for the same functional output, like the production of acid during caries progression [Peterson et al., 2011].

Although a metagenomic approach reveals the total genetic potential of a microbial community, it has to be remembered that the active fraction of this community may change under different conditions such as saliva production, time of day or time elapsed since the last meal, among others, and will of course change at different stages of biofilm formation. Thus, an alternative to detect the active microbial members and identify the genes expressed under given circumstances is to analyze the RNA extracted from the samples, in an approach known as metatranscriptomics. The pioneering RNA-based studies were performed with environmental samples where total extracted RNA was reverse-transcribed to CDNA, which is then sequenced by one of the NGS technologies [FriasLopez et al., 2008]. Recent work has applied this approach to human gut samples [Turnbaugh et al., 2010] and to an in vitro oral biofilm model [Frias-Lopez and DuranPinedo, 2012]. A limitation of this approach comes from the high percentage of rRNA present in bacterial samples, which typically accounts for over $90 \%$ of total RNA, and different methods have been applied to enrich the sample in mRNA before sequencing [Gosalbes et al., 2011]. To our knowledge, no metatranscriptomic studies of oral microbiota samples are available. However, our initial experiments show that the relative proportions of bacteria detected in the metatranscriptome and in the metagenome of a 24-hour dental plaque sample are very different, indicating that concrete species are metabolically active at each particular moment. Thus, a combination of different metagenomic and metatranscriptomic approaches can be complementary in studying the taxo- nomic composition, the functional output and the actively expressed genes in a given sample as well as detecting and characterizing specific functions of implied importance. Given the current limitations in the amount of DNA required for NGS techniques, most metagenomic studies have been done with large samples involving saliva or pooled dental plaque from different teeth. However, recent advances in sample preparation are reducing the amount of DNA and RNA needed, and future metagenomic studies should therefore aim at more precise samples involving specific locations, like the clinically defined stages of caries, which will help to evaluate the microbiota associated with caries initiation and progression.

\section{Metabolomic Approach: Recent Discoveries about the Metabolism of Microbial Communities}

Research on the microbial community has traditionally been subdivided into analyses of: (1) microbial composition, (2) microenvironments such as nutritional condition, $\mathrm{pH}$, reduction-oxidation potential etc., and (3) functions of the microbial community. Among them, the functions of the microbial community, such as metabolic activity, are crucial final outputs, because they relate directly to the pathogenicity of dental caries [Takahashi, 2005].

According to a recent biological concept, there is a linked biological hierarchy from genome to transcriptome/proteome to metabolome (fig. 1), which impacts on the biofilm phenotype and on disease outcome (i.e. caries lesion dynamics). The genome is a set of genes of an organism, which represents a series of information about which gene is used for what. A set of genes can be transcribed to a set of mRNAs (transcriptome) and translated to a set of proteins (proteome). The proteome represents the potential to function, i.e. metabolic reactions catalyzed by enzyme activities. A set of metabolites, the socalled metabolome, is then produced as the final output from the biological hierarchy. This hierarchy corresponds with the microbial research strategy described above. Applied to a microbial community like the oral biofilm, the metatranscriptome represents the expressed genes produced by the biofilm while the metaproteome is the microbial proteins produced by the biofilm, detectable by the analytical system. The metabolome ${ }^{1}$ is the final output of the metabolism of the microbial community, such

\footnotetext{
1 The term 'meta-metabolome' would be more appropriate in the future, although 'metabolome' is mainly used at present.
} 


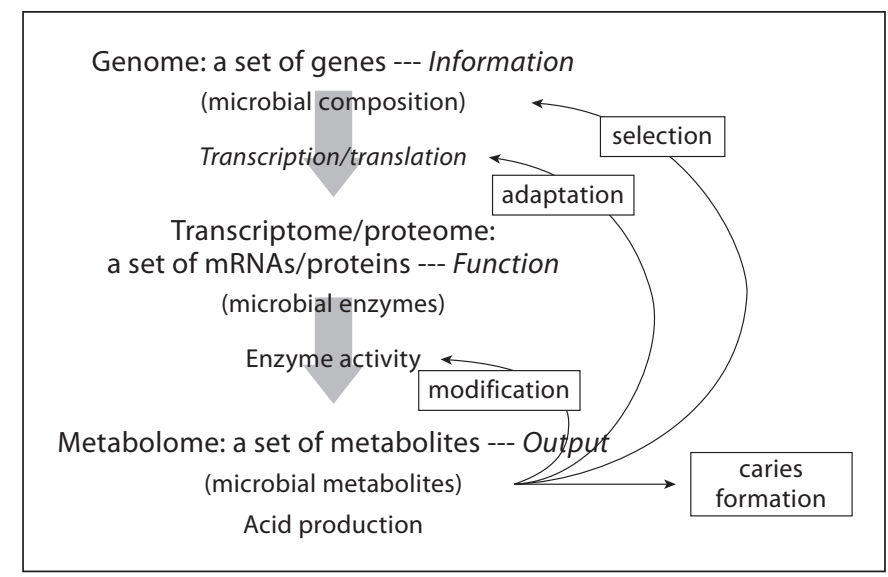

Fig. 1. Biological hierarchy from genome to transcriptome/proteome to metabolome, relevant to research strategy of the microbial community [Takahashi et al., 2012]. Reproduced with permission from the Journal of Oral Biosciences.

as acid or base production, which is directly associated with caries formation [Takahashi et al., 2012]. Each of these approaches provides an answer to a different question relating to the microbial community under study (fig. 2).

The biological hierarchy impinges on the biochemical and ecological processes in the dental microbial community (fig. 1). Thus, enzyme activities are influenced by environmental acidification (acid-induced modification of enzymatic activity) which also regulates transcription and translation (acid-induced adaptation through induction of proteins/enzymes). In addition, the acidified environment causes a shift of the microbial composition (acid-induced selection of microorganisms). This cycle will continue, as long as the environmental acidification continues [Takahashi and Nyvad, 2008, 2011]. According to this hypothesis, environmental acidification is the main driving force of the phenotypic and genotypic changes in the microbial community during the caries process. Therefore, to fully explain and understand the cariogenic potential of the microbial community at different stages of the caries process, it is important to learn about the metabolic activities relevant to environmental acidification of the bacteria. In fact, it has been postulated that studies of the metabolome may be more relevant for explaining caries activity than studies focusing exclusively on the microbiome [Takahashi and Nyvad, 2008].

Carbohydrate metabolism is a key issue in caries. The central carbon metabolism starts with classic glycolysis, the Embden-Meyerhof-Parnas (EMP) pathway, in which glucose is degraded into pyruvate, and, under anaerobic conditions, further degraded into lactate, formate and acetate. These pathways are shared by Streptococcus, Actinomyces and Lactobacillus. In the presence of oxygen, pyruvate is converted to acetate by Streptococcus and Lactobacillus, and lactate is converted to acetate by Actinomyces. In the presence of bicarbonate, abundantly contained in saliva, phosphoenolpyruvate is converted to succinate with bicarbonate assimilation, using part of the tricarboxylic acid (TCA) cycle. Actinomyces uses this metabolic pathway [Carlsson, 1986; Takahashi and Yamada, 1999; Takahashi et al., 2010]. These metabolic pathways have been elucidated, using single bacterial strains in laboratory studies. We do not know to what extent such pathways function in supragingival plaque in vivo. The amount of supragingival plaque that can be sampled from the oral cavity is too small for a conventional metabolic study. In order to overcome this difficulty, metabolome analysis is an excellent alternative.

Metabolome analysis (metabolomics) is the comprehensive identification and quantification of metabolites in biological systems, which is one of the most powerful approaches for metabolism research. In the 1960s, Minakami et al. [1965] succeeded in quantifying metabolic intermediates of the EMP pathway in human red blood cells by a photometry-coupled enzymatic method using purified glycolytic enzymes. This method was then modified and developed by the author's laboratory for oral bacteria, including oral Streptococcus and Actinomyces (see the introduction of Takahashi et al. [2010]). Later, a thin-layer chromatography using radio-labeled metabolic substrates [Conyers et al., 1976] and a nuclear magnetic resonance method [Ugurbil et al., 1978] were established. These studies clarified changes in the profile of glycolytic intermediates; however, these methods have long been restricted to the EMP pathway because of methodological limitations.

In the last two decades, metabolomics has developed rapidly, mainly due to the combination of chromatography or electrophoresis for the separation of metabolites with high resolution and mass spectrometry (MS) for the precise identification of biological molecules. Recently, capillary electrophoresis (CE) has been adopted for the separation of metabolites, since most metabolites are polar and ionic small molecules. CE-MS is thus suitable to separate and quantify metabolites concerning the central carbon metabolism, including the EMP pathway, the pentose-phosphate pathway and the TCA cycle [Soga et al., 2002, 2003]. Furthermore, CE-MS has been applied successfully for analysis of small oral samples [Taka- 


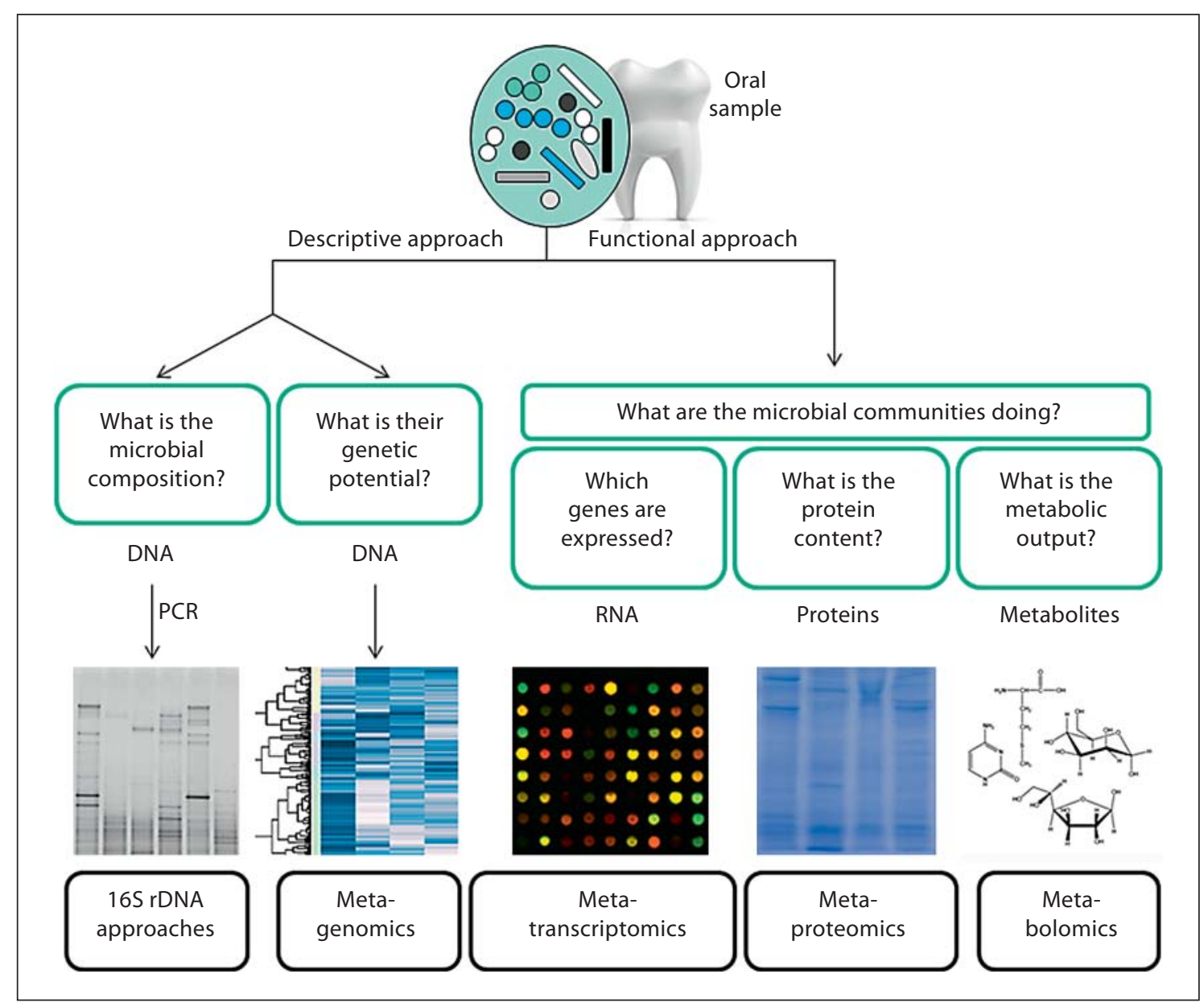

Fig. 2. Schematic representation of different 'omics' approaches to study oral microbial communities. DNA can be extracted from an oral sample to determine taxonomic composition by different $16 \mathrm{~S}$ rDNA approaches or to study the functions coded by the total gene content of the community (i.e. the metagenome). If RNA is extracted and sequenced, the obtained sequences (i.e. the metatranscriptome) will represent the global pattern of expressed genes in the active portion of the bacterial populations. The total protein and metabolic output of the community will be obtained by analyzing the metaproteome and metabolome by different mass spectrometry techniques. If the metagenomic approach provides information about the total genetic repertoire of the microbes, the metatranscriptomic, metaproteomic and metabolomic approaches give insights about the active organisms and functions at the moment of sampling. The 16S rDNA-based methodologies are cheaper than 'omics' approaches but do not provide information about the functional capacity and output of the oral community. Adapted from Zoetendal et al. [2008]. hashi et al., 2010; Washio et al., 2010]. Using the CE-MS system, as little as $10 \mathrm{mg}$ of supragingival plaque is needed to detect and quantify each of the metabolic intermediates of the central carbon metabolism. All the targeted metabolic intermediates in the EMP pathway, the pentose-phosphate pathway and the TCA cycle were identified and quantified from supragingival plaque, and the metabolome profile of supragingival plaque before and after glucose rinse in vivo were obtained [Takahashi et al., 2010]. In addition, it was revealed that the profiles of the metabolite change in supragingival plaque in the
EMP pathway, the pentose-phosphate pathway and the TCA cycle were similar to the profile obtained from a single bacterial strain of $S$. sanguinis, S. mutans, A. oris and $A$. naeslundii [Takahashi et al., 2010]. These results led us to support the novel idea that a microbial community consists of a tremendous number of diverse bacteria, but functions as one organism, a 'superorganism' [Buchen, 2010].

Metabolome analyses may also contribute to explaining the fundamental question in caries: What is a 'healthy' plaque? It is known that dental plaque has 'homeostasis' 
[Marsh and Martin, 1999]. In resting plaque, supragingival bacteria utilize endogenous energy sources such as saliva which contains many kinds of proteins, glycoproteins and urea. Proteins can be degraded to peptides and amino acids and then turned to acids and ammonia by bacteria, which possess an arginine deiminase pathway and general amino-acid degrading pathways. Glycoproteins can also be degraded to amino acids and sugars, the former can be consequently degraded to acids and ammonia and the latter can be degraded to acids. Urea is turned to ammonia and carbon dioxide by bacterial urease. So, supragingival bacteria have the ability to produce alkalis as well as acids. As a result, supragingival plaque $\mathrm{pH}$ can be stable, and demineralization and remineralization are balanced. When sugars are supplied to the oral cavity, plaque $\mathrm{pH}$ is decreased rapidly by bacterial acid production, and the $\mathrm{pH}$ slowly returns to the original level. This $\mathrm{pH}$ recovery is considered to be mainly due to salivary secretion, but alkali-producing activities can also contribute to $\mathrm{pH}$ recovery, as previously reviewed by Kleinberg [2002]. Metabolome analysis of the metabolic pathways of alkali production is likely to add new information about the nature of homeostasis of the microbial community.

Although still in its youth, metabolome analysis is a promising method that makes it possible to monitor the dynamic functions of metabolism in the oral microbial community in vivo. This new tool might enable us to assess the cariogenic potential of the dental microbial community, and to understand how the balance of the microbial community is maintained or the shifts between demineralization and remineralization. Metabolome analysis may also be applied to elucidate drug efficacy, from the classic cariostatic effects of fluoride [Takahashi and Washio, 2011] to new-generation cariespreventive agents, and might even serve to identify new biomarkers relevant to caries activity.

Metaproteomics is positioned between metagenomics/metatranscriptomics and metabolomics (fig. 1,2). The application of proteomics to oral biofilm may provide important information on the protein synthesis and the posttranslational modification of proteins. However, proteins produced by microorganisms in the oral biofilm are highly variable and cannot be distinguished clearly from host proteins, e.g. by differential proteomic analysis using a 2-dimensional electrophoresis. Further study is needed to overcome these issues for the metaproteomics of oral microbial communities, and preliminary work has been developed to set up appropriate protocols for sample treatment, MS and data analysis [Jagtap et al., 2012]. In the future, we believe that a combination of the different omics approaches will give a more complete and comprehensive view of the role that the oral microbiota plays in health and disease.

\section{The Significance of Site Specificity in Caries}

So far, most of the molecular studies of caries, whether genomic or metabolomic, have been performed on saliva samples or on pooled plaque samples, e.g. Becker et al. [2002], Aas et al. [2008], Takahashi et al. [2010] and Crielaard et al. [2011]. While this may to a certain extent be ascribed to the lack of the current molecular techniques in dealing with very small bacterial samples, such studies are not likely to add a new and detailed insight into the microbial and metabolic processes of caries at the site level. Saliva samples are merely proxy variables of caries and may, at best, represent a reflection of what happens in the microbial community during caries lesion development in vivo. This notion was recently supported by a study in which bacterial inocula retrieved from the saliva of individuals with different caries experiences failed to produce differences in the cariogenic potential of experimental microcosm biofilms [Azevedo et al., 2011].

As pointed out above, the pooling of plaque samples is another factor that may seriously confound the information gained from molecular studies of caries. Dental caries is a localized disease of the teeth [Fejerskov et al., 2008], and the carious processes are further modulated by intraoral and local environmental factors (for review, see Fejerskov et al. [1994]). Therefore, if we want to fully learn and understand the ecology of caries, we must adopt a microbial sampling strategy that takes into consideration gradients and compartmentalization in the oral cavity [Kleinberg and Jenkins, 1964] including the site-specific differences in salivary film velocity [Dawes et al., 1989] and glucose and hydrogen ion concentrations [Whetherall et al., 1988], the $\mathrm{pH}$ [Kleinberg and Jenkins, 1964] and the composition of the microbiota [Onisi et al., 1957; McNamara et al., 1979]. Moreover, local clinical features, such as the degree of protection (i.e. cavitation stage) and lesion activity [Nyvad et al., 1999] are important factors to bear in mind. It follows from this that microbial sampling for caries is an art that should not be passed on to the least-experienced clinician in the team. As microbial sampling is a crucial part of study design, it should preferably be performed by a professional with a solid knowledge of caries. 
Up till now, only a few molecular studies have adopted a site-specific sampling strategy for studying caries. Using such approaches, it has become clear that the bacterial community in root/dentinal caries shows considerable subject-to-subject variation [Preza et al., 2008] and is much more diverse than previously anticipated [Munson et al., 2004; Preza et al., 2008]. In a recent paper by Lima et al. [2011], there was an attempt to identify the microbiota of different layers of deep dentinal caries by targeting 28 oral candidate pathogens using reverse-capture checkerboard analysis. Contrary to expectations [Edwardsson, 1974], the authors did not reveal differences in the prevalence of the target bacteria between the different layers of caries. While this might be partly due to the checkerboard analysis targeting only a limited number of microbial species, it is more likely that the negative result could be ascribed to a lack of stringency with the sampling procedure. Thus, the study sample included occlusal lesions of variable clinical severity (cavitated as well as noncavitated lesions), the $\mathrm{pH}$ and ecology of which are known to differ quite substantially [Fejerskov et al., 1992]. The fact that site-specific sampling of caries lesions using well-defined clinical criteria is indeed scientifically meaningful was properly demonstrated in a study of root caries showing that the proportion of Bifidobacteriaceae was closely related to the activity of the lesions [Mantzourani et al., 2009].

It seems safe to resolve that the crude bacterial sampling techniques often used to study caries microbiology do not match up with the advanced molecular methods available today. There is a need for an increased focus on site-specific sampling of microbial communities for studying the molecular ecology of caries. Microbial sampling methods should match with the specific aim of study and reflect the current sciences about the clinical and histopathological features of caries. Moreover, new molecular technologies should be developed to enable analysis of small samples. In any case, it should be appreciated that sampling always destroys the natural structure and function of the microbial habitat, whereby potentially useful information about the ecology in vivo is lost. New molecular approaches applying confocal microscopy in combination with species-specific oligonucleotide probes and fluorescence in situ hybridization (FISH) and other fluorescence techniques are likely to expand our understanding of the spatial distribution and function of intact microbial communities on teeth [Dige et al., 2009; Zijnge et al., 2010; Marsh et al., 2011].

\section{Conclusion}

This review highlights the fact that the principle molecular method, 16S rRNA sequencing and subsequent population characterization, for studying the diversity of the oral microbiome and the microbiota associated with caries, is limited. New approaches including the metagenomic, metatranscriptomic, metaproteomic and metabolome analysis of oral biofilms, along with refined microbial sampling techniques, are required to improve our understanding of the ecology of caries. Such combined approaches will enable the genes expressed and the phenotypic characteristics of the biofilms at well-defined dental sites to be determined. Understanding the functioning, rather than just the composition of the microbial community, should be a high priority for caries microbiologists in the future.

\section{Summary Statements of the Symposium}

- Molecular oral microbiology is still in its youth.

- Cultivation studies are not outdated. We need live bacteria to learn what the bacteria are doing.

- Dental caries is a good model for studying the biological hierarchy of microbial communities.

- Site-specific sampling of bacteria for molecular analysis of caries is imperative to reflect the localized nature of the disease.

- The choice of molecular method depends on the research question to be addressed.

- NGS methods can be used to determine genetic potential and functioning of the oral biofilm and may enable the identification of biomarkers in saliva and plaque to predict caries status.

- Metabolome analysis can be an alternative approach to study the metabolic function of microbial communities, but its use for analysis of small site-specific samples may be premature.

\section{Acknowledgements}

Colgate Palmolive and GABA International are gratefully acknowledged for sponsoring the ORCA 2011 Saturday Afternoon Symposium.

\section{Disclosure Statement}

The authors declare that there are no conflicts of interest relating to the data and opinions presented in this paper. 


\section{References}

-Aas JA, Griffen AL, Dardis SR, Lee AM, Olsen I, Dewhirst FE, Leys EJ, Paster BJ: Bacteria of dental caries in primary and permanent teeth in children and young adults. J Clin Microbiol 2008;46:1407-1417.

-Alam S, Brailsford SR, Adams S, Allison C, Sheehy E, Zoitopoulos L, Kidd EA, Beighton D: Genotypic heterogeneity of Streptococcus oralis and distinct aciduric subpopulations in human dental plaque. Appl Environ Microbiol 2000;66:3330-3336.

-Alam S, Brailsford SR, Whiley RA, Beighton D: PCR-Based methods for genotyping viridans group streptococci. J Clin Microbiol 1999; 37:2772-2776.

Arif N, Sheehy EC, Do T, Beighton D: Diversity of Veillonella spp. from sound and carious sites in children. J Dent Res 2008;87:278282 .

-Azevedo MS, van der Sande FH, Romano AR, Cenci MS: Microcosm biofilms originating from children with different caries experience have similar cariogenicity under successive sucrose challenges. Caries Res 2011; 45:510-517.

- Becker MR, Paster BJ, Leys EJ, Moeschberger ML, Kenyon SG, Galvin JL, Boches SK, Dewhirst FE, Griffen AL: Molecular analysis of bacterial species associated with childhood caries. J Clin Microbiol 2002;40:10011009.

-Beighton D, Gilbert SC, Clark D, Mantzourani M, Al-Haboubi M, Ali F, Ransome E, Hodson N, Fenlon M, Zoitopoulos L, Gallagher J: Isolation and identification of Bifidobacteriaceae from human saliva. Appl Environ Microbiol 2008;74:6457-6460.

-Belda-Ferre P, Alcaraz LD, Cabrera-Rubio R Romero H, Simón-Soro A, Pignatelli M, Mira A: The oral metagenome in health and disease. ISME J 2011;6:46-56.

Berkowitz RJ, Jones P: Mouth-to-mouth transmission of the bacterium Streptococcus mutans between mother and child. Arch Oral Biol 1985;30:377-379.

-Bishop CJ, Aanensen DM, Jordan GE, Kilian M, Hanage WP, Spratt BG: Assigning strains to bacterial species via the internet. BMC Biol 2009;7:3.

-Bodilis J, Nsigue-Meilo S, Besaury L, Quillet L: Variable copy number, intra-genomic heterogeneities and lateral transfers of the $16 \mathrm{~S}$ rRNA gene in Pseudomonas. PLoS One 2012; 7:e35647.

Brailsford SR, Tregaskis RB, Leftwich HS, Beighton $\mathrm{D}$ : The predominant Actinomyces spp. isolated from infected dentin of active root caries lesions. J Dent Res 1999;78:1525-1534.

Buchen L: Microbiology: the new germ theory. Nature 2010;468:492-495.

Call DR, Borucki MK, Loge FJ: Detection of bacterial pathogens in environmental samples using DNA microarrays. J Microbiol Methods $2003 ; 53: 235-243$.
Carlsson J: Metabolic activities of oral bacteria; in Thylstrup A, Fejerskov O (eds): Textbook of Cariology. Copenhagen, Munksgaard, 1986, pp 74-106.

Choi EJ, Lee SH, Kim YJ: Quantitative real-time polymerase chain reaction for Streptococcus mutans and Streptococcus sobrinus in dental plaque samples and its association with early childhood caries. Int J Paediatr Dent 2009; 19:141-147.

Ciric L, Pratten J, Wilson M, Spratt DA: Development of a novel multi-triplex qPCR(q)PCR method for the assessment of bacterial community structure in oral populations. Environ Microbiol Rep 2010;2:770-774.

Cole JR, Wang Q, Cardenas E, Fish J, Chai B, Farris RJ, Kulam-Syed-Mohideen AS, McGarrell DM, Marsh T, Garrity GM, Tiedje JM: The Ribosomal Database Project: improved alignments and new tools for rRNA analysis. Nucleic Acids Res 2009;37(database issue): D141-D145.

Conyers RA, Newsholme EA, Brand K: A thinlayer-chromatographic method for the separation of sugar phosphates. Biochem Soc Trans 1976;4:1040-1042.

Crielaard W, Zaura E, Schuller AA, Huse SM, Montijn RC, Keijser BJ: Exploring the oral microbiota of children at various developmental stages of their dentition in the relation to their oral health. BMC Med Genomics 2011;4:22.

Dahlén G, Konradsson K, Eriksson S, Teanpaisan R, Piwat S, Carlén A: A microbiological study in relation to the presence of caries and calculus. Acta Odontol Scand 2010;68:199206.

Dawes C, Watanabe S, Biglow-Lecomte P, Dibdin GH: Estimation of the velocity of the salivary film at some different locations in the mouth. J Dent Res 1989;68:1479-1482.

de Lillo A, Ashley FP, Palmer RM, Munson MA, Kyriacou L, Weightman AJ, Wade WG: Novel subgingival bacterial phylotypes detected using multiple universal polymerase chain reaction primer sets. Oral Microbiol Immunol 2006;21:61-68.

Delorme C, Poyart C, Ehrlich SD, Renault P: Extent of horizontal gene transfer in evolution of streptococci of the salivarius group. J Bacteriol 2007;189:1330-1341.

Dewhirst FE, Chen T, Izard J, Paster BJ, Tanner AC, Yu WH, Lakshmanan A, Wade WG: The human oral microbiome. J Bacteriol 2010; 192:5002-5017.

Diaz-Torres ML, Villedieu A, Hunt N, McNab R, Spratt DA, Allan E, Mullany P, Wilson M: Determining the antibiotic resistance potential of the indigenous oral microbiota of humans using a metagenomic approach. FEMS Microbiol Lett 2006;258:257-262.

Dige I, Raarup MK, Nyengaard JR, Kilian M, Nyvad B: Actinomyces in initial dental biofilm formation. Microbiology 2009;155: 2116-2126.
Do T, Gilbert SC, Klein J, Warren S, Wade WG, Beighton D: Clonal structure of Streptococcus sanguinis strains isolated from endocarditis cases and the oral cavity. Mol Oral Microbiol 2011;26:291-302.

Do T, Jolley KA, Maiden MC, Gilbert SC, Clark D, Wade WG, Beighton D: Population structure of Streptococcus oralis. Microbiology 2009; 155:2593-2602.

Donati C, Hiller NL, Tettelin H, Muzzi A, Croucher NJ, Angiuoli SV, Oggioni M, Dunning Hotopp JC, Hu FZ, Riley DR, Covacci A, Mitchell TJ, Bentley SD, Kilian M, Ehrlich GD, Rappuoli R, Moxon ER, Masignani V: Structure and dynamics of the pan-genome of Streptococcus pneumoniae and closely related species. Genome Biol 2010;11:R107.

Edwardsson S: Bacterial studies on deep areas of carious dentine. Odontol Revy Suppl 1974; 32:1-132.

Enersen M: Porphyromonas gingivalis: a clonal pathogen? Diversities in housekeeping genes and the major fimbriae gene. J Oral Microbiol 2011;3.

Fejerskov O, Nyvad B, Kidd EAM: Pathology of dental caries; in Fejerskov O, Kidd EAM (eds): Dental Caries. The Disease and Its Clinical Management, ed 2. Oxford, Blackwell Munksgaard 2008, pp 19-48.

Fejerskov O, Nyvad B, Larsen MJ: Human experimental caries models: Intra-oral environmental variability. Adv Dent Res 1994;8: 134-143.

Fejerskov O, Scheie AA, Manji F: The effect of sucrose on plaque $\mathrm{pH}$ in the primary and permanent dentition of caries-inactive and -active Kenyan children. J Dent Res 1992; 71:25-31.

Frank JA, Reich CI, Sharma S, Weisbaum JS, Wilson BA, Olsen GJ: Critical evaluation of two primers commonly used for amplification of bacterial 16S rRNA genes. Appl Environ Microbiol 2008;74:2461-2470.

Frias-Lopez J, Duran-Pinedo A: Effect of periodontal pathogens on the metatranscriptome of a healthy multispecies biofilm model. J Bacteriol 2012;194:2082-2095.

-Frias-Lopez J, Shi Y, Tyson GW, Coleman ML, Schuster SC, Chisholm SW, Delong EF: Microbial community gene expression in ocean surface waters. Proc Natl Acad Sci USA 2008; 105:3805-3810.

Ghai R, Martin-Cuadrado AB, Molto AG, Heredia IG, Cabrera R, Martin J, Verdú M, Deschamps P, Moreira D, López-García P, Mira A, Rodriguez-Valera F: Metagenome of the Mediterranean deep chlorophyll maximum studied by direct and fosmid library 454 pyrosequencing. ISME J 2010;4:1154-1166.

-Gosalbes MJ, Durbán A, Pignatelli M, Abellan JJ, Jiménez-Hernández $\mathrm{N}$, Pérez-Cobas AE, Latorre A, Moya A: Metatranscriptomic approach to analyze the functional human gut microbiota. PLoS One 2011;6:e17447. 
-Henssge U, Do T, Radford DR, Gilbert SC, Clark D, Beighton D: Emended description of Actinomyces naeslundii and descriptions of Actinomyces oris sp. nov. and Actinomyces johnsonii sp. nov., previously identified as Actinomyces naeslundii genospecies 1,2 and WVA 963. Int J Syst Evol Microbiol 2009;59: 509-516.

- Jagtap P, McGowan T, Brandhakavi S, Zheng JT, Seymour S, Griffin TJ, Rudney JD: Deep metaproteomic analysis of salivary supernatant. Proteomics 2012;12:992-1001.

Jiang W, Jiang Y, Li C, Liang J: Investigation of supragingival plaque microbiota in different caries status of Chinese preschool children by denaturing gradient gel electrophoresis. Microb Ecol 2011;61:342-352.

-Jünemann S, Prior K, Szczepanowski R, Harks I, Ehmke B, Goesmann A, Stoye J, Harmsen D: Bacterial community shift in treated periodontitis patients revealed by Ion Torrent 16S rRNA gene amplicon sequencing. PLoS One 2012;7:e41606.

Kanasi E, Johansson I, Lu SC, Kressin NR, Nunn ME, Kent R Jr, Tanner AC: Microbial risk markers for childhood caries in pediatricians' offices. J Dent Res 2010;89:378-383.

- Keijser BJ, Zaura E, Huse SM, van der Vossen JM, Schuren FH, Montijn RC, ten Cate JM, Crielaard W: Pyrosequencing analysis of the oral microflora of healthy adults. J Dent Res 2008;87:1016-1020.

Kleinberg I: A mixed-bacteria ecological approach to understanding the role of the oral bacteria in dental caries causation: an alternative to Streptococcus mutans and the specific-plaque hypothesis. Crit Rev Oral Biol Med 2002;13:108-125.

Kleinberg I, Jenkins GH: The $\mathrm{pH}$ of dental plaques in different areas of the mouth before and after meals and their relationship to the $\mathrm{pH}$ and rate of flow of resting saliva. Arch Oral Biol 1964;9:493-515.

Kroes I, Lepp PW, Relman DA: Bacterial diversity within the human subgingival crevice. Proc Natl Acad Sci USA 1999;96:14547-14552.

- Li L, Hsiao WW, Nandakumar R, Barbuto SM, Mongodin EF, Paster BJ, Fraser-Liggett CM, Fouad AF: Analyzing endodontic infections by deep coverage pyrosequencing. J Dent Res 2010;89:980-984.

Li Y, Caufield PW: The fidelity of initial acquisition of mutans streptococci by infants from their mothers. J Dent Res 1995;74:681-685.

Li Y, Ge Y, Saxena D, Caufield PW: Genetic profiling of the oral microbiota associated with severe early-childhood caries. J Clin Microbiol 2007;45:81-87.

- Lima KC, Coelho LT, Pinheiro IVA, Rocas IN, Siqueira JF Jr: Microbiota of dentinal caries as assessed by reverse-capture checkerboard analysis. Caries Res 2011;45:21-30.

- Ling Z, Kong J, Jia P, Wei C, Wang Y, Pan Z, Huang W, Li L, Chen H, Xiang C: Analysis of oral microbiota in children with dental caries by PCR-DGGE and barcoded pyrosequencing. Microb Ecol 2010;60:677-690.
Maiden MC, Bygraves JA, Feil E, Morelli G, Russell JE, Urwin R, Zhang Q, Zhou J, Zurth K, Caugant DA, Feavers IM, Achtman M, Spratt BG: Multilocus sequence typing: a portable approach to the identification of clones within populations of pathogenic microorganisms. Proc Natl Acad Sci USA 1998;95:3140 3145.

Mantzourani M, Fenlon M, Beighton D: Association between Bifidobacteriaceae and the clinical severity of root caries lesions. Oral Microbiol Immunol 2009;24:32-37.

Marsh PD: Microbial ecology of dental plaque and its significance in health and disease. Adv Dent Res 1994;8:263-271.

Marsh PD, Martin VM: Dental plaque; in Marsh PD, Martin VM (eds): Oral Microbiology. Oxford, Wright, 1999, pp 58-81.

Marsh PD, Moter A, Devine DA: Dental plaque biofilms: communities, conflict and control. Periodontology 2000 2011;55:16-35.

Mattos-Graner RO, Li Y, Caufield PW, Duncan M, Smith DJ: Genotypic diversity of mutans streptococci in Brazilian nursery children suggests horizontal transmission. J Clin Microbiol 2001;39:2313-2316.

McNamara TF, Friedman BK, Kleinberg I: The microbial composition of human incisor tooth plaque. Arch Oral Biol 1979;24:91-95.

Metzker ML: Sequencing technologies - the next generation. Nat Rev Genet 2010;11:31-46.

Michon AL, Aujoulat F, Roudière L, Soulier O, Zorgniotti I, Jumas-Bilak E, Marchandin H: Intragenomic and intraspecific heterogeneity in rrs may surpass interspecific variability in a natural population of Veillonella. $\mathrm{Mi}-$ crobiology 2010;156:2080-2091.

-Minakami S, Suzuki C, Saito T, Yoshikawa H Studies on erythrocyte glycolysis. I. Determination of the glycolytic intermediates in human erythrocytes. J Biochem 1965;58: 543-550.

Mullany P, Hunter S, Allan E: Metagenomics of dental biofilms. Adv Appl Microbiol 2008; 64:125-136.

-Munson MA, Banerjee, Watson TF, Wade WG: Molecular analysis of the microflora associated with dental caries. J Clin Microbiol 2004;42:3023-3029.

-Muyzer G, De Waal EC, Uitterlinden AG: Profiling of complex microbial populations by denaturing gradient gel electrophoresis analysis of polymerase chain reaction-amplified genes coding for 16S rRNA. Appl Environ Microbiol 1993;59:695-700.

Nakano K, Lapirattanakul J, Nomura R, Nemoto $\mathrm{H}$, Alaluusua S, Grönroos L, Vaara M, Hamada S, Ooshima T, Nakagawa I: Streptococcus mutans clonal variation revealed by multilocus sequence typing. J Clin Microbiol 2007;45:2616-2625.

- Naser SM, Dawyndt P, Hoste B, Gevers D, Vandemeulebroecke K, Cleenwerck I, Vancanneyt M, Swings J: Identification of lactobacilli by pheS and rpoA gene sequence analyses. Int J Syst Evol Microbiol 2007;57: 2777-2789.
Niazi SA, Clarke D, Do T, Gilbert SC, Mannocci F, Beighton D: Propionibacterium acnes and Staphylococcus epidermidis isolated from refractory endodontic lesions are opportunistic pathogens. J Clin Microbiol 2010;48: 3859-3869.

Nyvad B, Machiulskiene V, Baelum V: Reliability of a new caries diagnostic system differentiating between active and inactive caries lesions. Caries Res 1999;33:252-260.

>Olson JC, Cuff CF, Lukomski S, Lukomska E, Canizales Y, Wu B, Crout RJ, Thomas JG, McNeil DW, Weyant RJ, Marazita ML, Paster BJ, Elliott T: Use of 16S ribosomal RNA gene analyses to characterize the bacterial signature associated with poor oral health in West Virginia. BMC Oral Health 2011;11:7.

Onisi M, Tachibana Y, Takakuwa S, Ishioka K, Nakamura T: Preferential sites of the urea hydrolyzing organisms in the mouth. Tokyo Med Dent Bull 1957;4:253-257.

- Palmer CA, Kent R Jr, Loo CY, Hughes CV, Stutius E, Pradhan N, Dahlan M, Kanasi E, Arevalo Vasquez SS, Tanner AC: Diet and cariesassociated bacteria in severe early childhood caries. J Dent Res 2010;89:1224-1229.

Palmer RJ Jr, Darveau R, Lamont RJ, Nyvad B, Teles RP: Human oral bacterial biofilms: Composition, dynamics and pathogenesis; in Bjarnsholt T, Østrup Jensen P, Moser C, Høiby N (eds): Biofilm Infections. New York, Springer, 2011, pp 35-68.

Paster BJ, Dewhirst FE: Molecular microbial diagnosis. Periodontology 2000 2009;51:3844.

- Paster BJ, Olsen I, Aas JA, Dewhirst FE: The breadth of bacterial diversity in the human periodontal pocket and other oral sites. Periodontology 2000 2006;42:80-87.

$\checkmark$ Pei AY, Oberdorf WE, Nossa CW, Agarwal A, Chokshi P, Gerz EA, Jin Z, Lee P, Yang L, Poles M, Brown SM, Sotero S, Desantis T, Brodie E, Nelson K, Pei Z: Diversity of $16 \mathrm{~S}$ rRNA genes within individual prokaryotic genomes. Appl Environ Microbiol 2010;76: 3886-3897.

Peterson SN, Snesrud E, Schork NJ, Bretz WA: Dental caries pathogenicity: a genomic and metagenomic perspective. Int Dent J 2011; 61(suppl 1):11-22.

Pham LC, Hoogenkamp MA, Exterkate RA, Terefework Z, de Soet JJ, ten Cate JM, Crielaard W, Zaura E: Effects of Lactobacillus rhamnosus GG on saliva-derived microcosms. Arch Oral Biol 2011;56:136-147.

Preza D, Olsen I, Aas JA, Willumsen T, Grinde B, Paster BJ: Bacterial profiles of root caries in elderly patients. J Clin Microbiol 2008;46: 2015-2021.

Preza D, Olsen I, Willumsen T, Boches SK, Cotton SL, Grinde B, Paster BJ: Microarray analysis of the microflora of root caries in elderly. Eur J Clin Microbiol Infect Dis 2009;28:509517.

Rogers AH: Evidence for the transmissibility of human dental caries. Aust Dent J 1977;22: 53-56. 
Schadt EE, Turner S, Kasarskis A: A window into third-generation sequencing. Hum $\mathrm{Mol}$ Genet 2010;19(R2):R227-R240.

-Seville LA, Patterson AJ, Scott KP, Mullany P, Quail MA, Parkhill J, Ready D, Wilson M, Spratt D, Roberts AP: Distribution of tetracycline and erythromycin resistance genes among human oral and fecal metagenomic DNA. Microb Drug Resist 2009; 15:159-166.

- Sipos R, Székely AJ, Palatinszky M, Révész S, Márialigeti K, Nikolausz M: Effect of primer mismatch, annealing temperature and PCR cycle number on $16 \mathrm{~S}$ rRNA gene-targetting bacterial community analysis. FEMS Microbiol Ecol 2007;60:341-350.

- Sissons CH, Anderson SA, Wong L, Coleman MJ, White DC: Microbiota of plaque micro cosm biofilms: effect of three times daily sucrose pulses in different simulated oral environments. Caries Res 2007;41:413-422.

-Smith CJ, Osborn AM: Advantages and limitations of quantitative PCR (Q-PCR)-based approaches in microbial ecology. FEMS Microbiol Ecol 2009;67:6-20.

Socransky SS, Haffajee AD, Smith C, Martin L, Haffajee JA, Uzel NG, Goodson JM: Use of checkerboard DNA-DNA hybridization to study complex microbial ecosystems. Oral Microbiol Immunol 2004;19:352-362.

- Soga T, Ohashi Y, Ueno Y, Naraoka H, Tomita M, Nishioka T: Quantitative metabolome analysis using capillary electrophoresis mass spectrometry. J Proteome Res 2003;2:488-494.

- Soga T, Ueno Y, Naraoka H, Ohashi Y, Tomita M, Nishioka T: Simultaneous determination of anionic intermediates for Bacillus subtilis metabolic pathways by capillary electrophoresis electrospray ionization mass spectrometry. Anal Chem 2002;74:2233-2239.

- Sorek R, Zhu Y, Creevey CJ, Francino MP, Bork P, Rubin EM: Genome-wide experimental determination of barriers to horizontal gene transfer. Science 2007;318:1449-1452.

- Stahlhut SG, Schroll C, Harmsen M, Struve C, Krogfelt KA: Screening for genes involved in Klebsiella pneumoniae biofilm formation using a fosmid library. FEMS Immunol Med Microbiol 2010;59:521-524.

Takahashi N: Microbial ecosystem in the oral cavity: metabolic diversity in an ecological niche and its relationship with oral diseases; in Watanabe M, Takahashi N, Takada H (eds): Interface Oral Health Science, International Congress Series 1284. Oxford, Elsevier, 2005, pp 103-112.
Takahashi N, Nyvad B: Caries ecology revisited: microbial dynamics and the caries process. Caries Res 2008;42:409-418.

Takahashi N, Nyvad B: The role of bacteria in the caries process: ecological perspectives. J Dent Res 2011;90:294-303.

Takahashi N, Washio J: Metabolomic effects of xylitol and fluoride on plaque biofilm in vivo. J Dent Res 2011;90:1463-1468.

Takahashi N, Washio J, Mayanagi G: Metabolomics of supragingival plaque and oral bacteria. J Dent Res 2010;89:1383-1388.

Takahashi N, Washio J, Mayanagi G: Metabolomic approach to oral biofilm characterization. J Oral Biosci 2012;54:138-143.

Takahashi N, Yamada T: Glucose and lactate metabolism by Actinomyces naeslundii. Crit Rev Oral Biol Med 1999;10:504-518.

Terefework Z, Pham CL, Prosperi AC, Entius MM, Errami A, van Spanning RJ, Zaura E, Ten Cate JM, Crielaard W: MLPA diagnostics of complex microbial communities: relative quantification of bacterial species in oral biofilms. J Microbiol Methods 2008;75:558565.

Touchon M, Hoede C, Tenaillon O, Barbe V Baeriswyl S, Bidet P, Bingen E, Bonacorsi S, Bouchier C, Bouvet O, Calteau A, Chiapello H, Clermont O, Cruveiller S, Danchin A Diard M, Dossat C, Karoui ME, Frapy E, Garry L, Ghigo JM, Gilles AM, Johnson J, Le Bouguénec C, Lescat M, Mangenot S, Martinez-Jéhanne V, Matic I, NassifX, Oztas S, Petit MA, Pichon C, Rouy Z, Ruf CS, Schneider D, Tourret J, Vacherie B, Vallenet D, Médigue C, Rocha EP, Denamur E: Organised genome dynamics in the Escherichia coli species results in highly diverse adaptive paths. PLoS Genet 2009; 5:e1000344.

Turnbaugh PJ, Quince C, Faith JJ, et al: Organismal, genetic, and transcriptional variation in the deeply sequenced gut microbiomes of identical twins. Proc Natl Acad Sci USA 2010;107:7503-7508.

Ugurbil K, Rottenberg H, Glynn P, Shulman RG: ${ }^{31} \mathrm{P}$ nuclear magnetic resonance studies of bioenergetics and glycolysis in anaerobic Escherichia coli cells. Proc Natl Acad Sci USA 1978;75:2244-2248.

van Houte J, Lopman J, Kent R: The final pH of bacteria comprising the predominant flora on sound and carious human root and enamel surfaces. J Dent Res 1996;75:1008-1014.
Vásquez A, Molin G, Pettersson B, Antonsson M, Ahrné S: DNA-based classification and sequence heterogeneities in the $16 \mathrm{~S}$ rRNA genes of Lactobacillus casei/paracase $i$ and related species. Syst Appl Microbiol 2005;28: 430-441.

Vos M, Quince C, Pijl AS, de Hollander M, Kowalchuk GA: A comparison of rpoB and $16 \mathrm{~S}$ rRNA as markers in pyrosequencing studies of bacterial diversity. PLoS One 2012;7: e30600.

-Wade WG: Unculturable bacteria-the uncharacterized organisms that cause oral infections. J R Soc Med 2002;95:81-83.

$\checkmark$ Wade WG: Has the use of molecular methods for the characterization of the human oral microbiome changed our understanding of the role of bacteria in the pathogenesis of periodontal disease? J Clin Periodontol 2011;38: 7-16.

Wagner M, Smidt H, Loy A, Zhou J: Unravelling microbial communities with DNA-microarrays: challenges and future directions. $\mathrm{Mi}-$ crob Ecol 2007;53:498-506.

-Washio J, Mayanagi G, Takahashi N: Challenge to metabolomics of oral biofilm. J Oral Biosci 2010;52:225-232.

Waterhouse JC, Russell RR: Dispensable genes and foreign DNA in Streptococcus mutans. Microbiology 2006;152:1777-1788.

Whetherall JA, Duggal MS, Robinson C, Curzon MEJ: Site-specific differences in human dental plaque $\mathrm{pH}$ after sucrose rinsing. Arch Oral Biol 1988;33:871-873.

Xie G, Chain PS, Lo CC, Liu KL, Gans J, Merritt J, Qi F: Community and gene composition of a human dental plaque microbiota obtained by metagenomic sequencing. Mol Oral Microbiol 2010;25:391-405.

> Yang F, Zeng X, Ning K, Liu KL, Lo CC, Wang W, Chen J, Wang D, Huang R, Chang X, Chain PS, Xie G, Ling J, Xu J: Saliva microbiomes distinguish caries-active from healthy human populations. ISME J 2012;6:1-10.

Zaura E: Next-generation sequencing approaches to understanding the oral microbiome. Adv Dent Res 2012;24:81-85.

Zijnge V, van Leeuwen MBM, Degener JE, Abbas F, Thurnheer T, Gmür R, Harmsen HJM: Oral biofilm architecture on natural teeth. PLoS One 2010;5:e9321.

Zoetendal EG, Rajilic-Stojanovic M, de Vos WM: High-throughput diversity and functionality analysis of the gastrointestinal tract microbiota. Gut 2008;57:1605-1615. 